\title{
Investigando o desempenho de projetos conduzidos em estruturas matriciais
}

José Aloysio de Souza Júnior

Mestre em Comunicações Digitais pela Universidade de Tecnologia Chalmers Gotenburgo, Suécia. Especialista em Gerenciamento de Projetos pela UFRJ. Engenheiro de Telecomunicações formado pela UFBA. Engenheiro de Telecomunicações Sênior da Petrobras. Gerente de projetos com certificações PMP e PMI-RMP pelo PMI, Rio de Janeiro,Brasil .

Luiz Fernando Alves da Rocha

Mestre em Engenharia Industrial pela UFRJ, graduado em Engenharia Mecânica pela mesma instituição. Possui certificações PMP, IPMA-C e Prince2 practitioner. Exerceu cargos executivos nas empresas Andersen Consulting e Deloitte no Brasil, nos Estados Unidos e na Europa.Diretor da Odysseus Consulting, vicepresidente do IPMA-Brasil e pesquisador convidado da UFR, Rio de Janeiro, Brasil

\section{Editor Científico: José Edson Lara}

Organização Comitê Científico

Double Blind Review pelo SEER/OJS

Recebido em 09.07.2016

Aprovado em 28.06.2017$$
\text { (a) (1) (9) }
$$

Este trabalho foi licenciado com uma Licença Creative Commons - Atribuição - Não Comercial 3.0 Brasil
} 


\title{
Resumo
}

As estruturas organizacionais matriciais aumentam a interação entre os profissionais das equipes de projetos, o que potencializa a existência de conflitos. Trata-se, portanto, de um tema de grande relevância, visto que os conflitos nas equipes envolvidas, quando mal administrados, podem causar transtornos organizacionais, reduzir o desempenho dos projetos, além de gerar estresse e improdutividade nos componentes das equipes. A influência do conflito no desempenho dos projetos conduzidos em estruturas matriciais é objeto de estudo deste relato técnico. A bibliografia mais recente na área de gerenciamento das partes interessadas é apresentada e é correlacionada a um estudo de caso de projetos conduzidos em uma empresa do ramo de óleo e gás. A influência do conflito em projetos matriciais é discutida ao final do texto.

Palavras chave: Gestão de projetos; Estruturas organizacionais; Indústria de óleo e gás; Gerenciamento de partes interessadas; Telecomunicações.

\section{Investigating the performance of projects conducted in a matrix organizational structure}

\begin{abstract}
Matrix organizational structures increase the interaction among project teams, which provides additional source for organizational conflicts. Therefore, it's a matter of great importance since the conflicts may cause organizational misbehavior, poor project performance, generate tensions, stress, and reduce employee productivity when mismanaged. Conflicts influence on the performance of projects conducted in matrix organizational structure is the subject of study of this technical report. The most recent literature in the domain of stakeholder management is presented and it is correlated to a case study of projects held in an oil and gas company. The influence of conflict on matrix projects is discussed at the end of the text.
\end{abstract}

Keywords: Project Management; Organizational structures; Oil and gas industry; Stakeholder management; Telecommunications.

\section{Investigando el desempeño de los proyectos organizados en estructuras matriciales}

\section{Resumen}

Las estructuras organizacionales matriciales aumentan la interacción entre los equipos de proyecto, lo que proporciona una fuente adicional de conflictos organizacionales. Los análisis de los conflictos son por ello aspectos relevantes porque pueden causar mal ambiente organizacional, pobre desempeño del proyecto, generar tensiones y stress además de reducir la productividad de los empleados cuando mal manejados. La influencia de los conflictos en el desempeño de los 
proyectos organizados en estructuras matriciales es el tema de estudio de este informe técnico. Se presenta la literatura más reciente en el ámbito de la gestión de los interesados y se correlaciona con un estudio de casos de proyectos realizados en una empresa de petróleo y gas. La influencia del conflicto en los proyectos matriciales se discute al final del texto.

Palabras clave: Gestión de proyectos; Estructuras organizacionales; Industria de petróleo y gas; Gestión de los interesados; Telecomunicaciones.

\section{Introdução}

As atividades de operação e projetos são claramente distintas nas organizações. O PMI 5 $5^{\text {a }}$ edição (2013) define as atividades de operação como esforços contínuos que geram saídas repetitivas de acordo com os padrões institucionalizados no ciclo de vida do produto. É possível identificar pontos comuns de interface entre as atividades de projeto e operação para qualquer empresa: no desenvolvimento de um novo produto; na melhoria das atividades de operações; no encerramento do projeto; até o fim do ciclo de vida do produto.

Para projetos conduzidos em estruturas matriciais, as equipes de projetos e de operações buscam compartilhar recursos e tomar decisões em conjunto. Esta situação aumenta a possibilidade de conflito entre estas equipes. A característica principal da estrutura matricial é a separação na organização dos papéis do gerente de operações e do gerente de projeto: não há subordinação hierárquica entre eles, podendo inclusive pertencer a estruturas hierárquicas diferentes.

Sbragia (1989) afirma que, ao lado de todas as vantagens da estrutura matricial como solução para ambientes com intensa necessidade de integração e interdisciplinaridade, o conflito imposto por este tipo de estrutura, acima de um nível crítico, pode causar improdutividade. O conflito pode ser compreendido como posições antagônicas entre as partes envolvidas que perturbam a ação ou a tomada de decisão.

A análise do conflito e sua influência nos resultados do projeto é tema de grande relevância frente a sua possível influência negativa sobre estes resultados. Posições antagônicas entre as gerências de operações e de projeto podem causar transtornos organizacionais e precisam ser trabalhadas, sobre pena de reduzir o desempenho dos projetos, além de causar estresse e improdutividade nos componentes das equipes. O desafio adicional do gerente de projeto, além de 
atender às clássicas restrições de prazo, custo e escopo é garantir o envolvimento da equipe de operações que eventualmente compõe sua própria equipe de projetos.

Este relato técnico pretende discutir a influência do conflito na condução de projetos matriciais na gerência de Tecnologia da Informação e Telecomunicações (TIC) de uma empresa do ramo de óleo e gás. A abordagem utilizada para suportar esta discussão é um estudo de campo aplicado a projetos de tecnologia em equipes matricialmente organizadas. Uma pesquisa bibliográfica é apresentada para subsidiar a discussão e técnicas verificadas na bibliografia são comentadas com a proposta de auxiliar o gerente de projeto a garantir o envolvimento da equipe matricial em prol do alcance do sucesso nos objetivos do seu projeto.

\section{$1 \quad$ Referencial teórico}

\subsection{Partes interessadas e os conflitos que dela emergem.}

O PMI, 5ª edição (PMI 2013), define parte interessada como "um indivíduo, grupo ou organização que pode afetar, ser afetado ou sentir-se afetado por uma decisão, atividade ou resultado do projeto". As diferentes partes interessadas têm interesses e expectativas, muitas vezes conflitantes, que contribuem positiva ou negativamente para o sucesso do projeto. $O$ envolvimento das partes interessadas é bastante diversificado: desde contribuições ocasionais até o patrocínio total do projeto. O gerenciamento de partes interessadas, portanto, consiste em identificar todos os grupos que podem causar impacto nos resultados do projeto, analisar suas expectativas e desenvolver estratégias de gerenciamento adequadas para o seu engajamento nas decisões e durante a execução do projeto.

A visão clássica do gerenciamento de partes interessadas é entendida a partir da definição de Freeman (1984), que afirma que "stakeholders são qualquer grupo ou indivíduo que afetam ou são afetados pelo atingimento dos objetivos organizacionais". O autor vai além e classifica as partes interessadas em principais e secundárias, o que possibilita a diferenciação e facilita a destinação de recursos, considerando que as organizações têm que maximizar a aplicação dos recursos disponíveis. Antes de Freeman (1984), Pfeffer e Salancik (1978) já consideravam as partes interessadas como provedores de recursos. 
Mitchell (1997) estabelece uma visão mais restritiva sobre partes interessadas relevantes. Para esse autor, as partes interessadas "são aqueles grupos relevantes que tem influência ou são influenciados pelos interesses diretos das organizações". A visão de Mitchell reforça o ponto de vista de Freeman de que os stakeholders relevantes devem receber mais recursos das organizações, enquanto que os demais devem ser apenas monitorados.

Huemann, Eskerod e Ringhofer (2016) propõem uma nova visão ao abordar o gerenciamento para as partes interessadas. Nesta visão holística, todos os stakeholders são dignos de atenção pela corporação de forma independente da sua capacidade de ameaçar ou auxiliar os interesses organizacionais. Os gerentes de projeto são convidados a buscar soluções ganha-ganha (entendidas como boas o suficiente) mesmo em situações de conflito de interesses; soluções de compromisso não são aceitas. A abordagem de gerenciamento para partes interessadas encaixase na perspectiva de desenvolvimento sustentável, que implica considerar não só as partes interessadas atuais como também as futuras, independentemente do seu posicionamento em quadrantes de poder, legitimidade e urgência, preservando desta maneira o desenvolvimento das futuras gerações.

Huemann, Eskerod e Ringhofer (2016) entendem os projetos como sistemas sociais. Os sistemas sociais são sistemas de comunicação que tomam decisões e vão formando o seu contorno próprio. Projetos neste contexto são organizações temporárias, que se diferenciam do ambiente nos quais estão inseridas, definidas em função das suas decisões. Os membros do projeto fazem parte do ambiente interno ao projeto, ao passo que todos os outros aspectos são pertencentes ao ambiente externo. Na teoria dos sistemas, as partes interessadas podem ser influenciadas apenas indiretamente, sendo decisão deles se engajar ou não no projeto.

Sob esta perspectiva, o gerenciamento para os stakeholders, diferentemente de ser compreendido como um sistema linear, de entradas e saídas, é um sistema social, baseado em situações complexas. Por esta razão, é preciso dotar os gerentes de projetos de ferramentas que facilitem a compreensão dessas relações e de sua complexidade. Huemann, Eskerod e Ringhofer (2016) sugerem a aplicação dos métodos de constelação sistêmica para tornar estes relacionamentos mais visíveis. Tais métodos têm berço na terapia familiar, a partir dos estudos da terapeuta Virginia Satir, posteriormente aprofundados por seus alunos, entre eles 0 
psicoterapeuta alemão Bert Hellinger. A constelação sistêmica, aplicada ao mundo corporativo, permite a simulação de relações complexas através de figuras desenhadas num quadro negro, ou através da dramatização pela interpretação das partes interessadas envolvidas no projeto em estudo. O desenho inicial da realidade vai sendo modificado à medida que os participantes interagem, construindo uma situação final que representa a visão do conjunto dos participantes. Os métodos de constelação sistêmica são também muito usados em outras aplicações, como desenvolvimento de equipes e cultura organizacional, suporte para inovação, implementação de estratégias, resolução de situações-problemas e no gerenciamento de projetos.

Por fim, Huemann, Eskerod e Ringhofer (2016) sugerem que o gerenciamento de partes interessadas e o gerenciamento para partes interessadas são extremos de uma linha contínua, cabendo entre eles diversas possibilidades. Diferentes fases do projeto requerem diferentes abordagens com os stakeholders. Além disto, há inúmeras combinações das duas abordagens entre diferentes grupos de partes interessadas. A Tabela 1 estabelece diferenças entre as duas abordagens.

\section{Tabela 1}

Diferenças entre as abordagens com partes interessadas

\begin{tabular}{|c|c|c|}
\hline \multicolumn{3}{|c|}{ Diferenças entre as abordagens com partes interessadas } \\
\hline & Gerenciamento das partes interessadas & Gerenciamento para as partes interessadas \\
\hline $\begin{array}{l}\text { Percepção das partes } \\
\text { interessadas }\end{array}$ & $\begin{array}{l}\text { Partes interessadas são instrumentos para atingir o } \\
\text { sucesso do projeto ou são ignoradas }\end{array}$ & Partes interessadas são fontes de ideias e alternativas \\
\hline $\begin{array}{l}\text { Partes interessadas } \\
\text { consideradas no } \\
\text { processo }\end{array}$ & $\begin{array}{l}1 \text { - A parte interessada mais importante é o investidor; } \\
2 \text { - Apenas as partes interessadas mais importantes são } \\
\text { levadas em consideração; } \\
3 \text { - Interesses das partes interessadas diferentes dos } \\
\text { interesses do projeto são considerados como } \\
\text { obstáculos para o alcance do sucesso do projeto. }\end{array}$ & $\begin{array}{l}1 \text { - Muitos / todas as partes interessadas são } \\
\text { consideradas e os seus diferentes interesses são } \\
\text { avaliados; } \\
2 \text { - Partes interessadas são explicitamente convidadas a } \\
\text { serem co-responsáveis pelo atingimento dos } \\
\text { resultados do projeto que beneficiarão grande grupo } \\
\text { dos stakeholders. }\end{array}$ \\
\hline $\begin{array}{l}\text { Entendimento sobre o } \\
\text { confilto }\end{array}$ & Conflito é ruim e deve ser evitado & $\begin{array}{l}\text { Conflito é inerente ao projeto, pois diferentes partes } \\
\text { interessadas tem interesses distintos. Conflito não é } \\
\text { considerado como ruim e uma cultura para lidar com } \\
\text { conflitos e contradições deve ser estabelecida no } \\
\text { projeto. }\end{array}$ \\
\hline Valores & $\begin{array}{l}1 \text { - Orientação manipulativa, muitas vezes considerada } \\
\text { como falta de ética; } \\
2 \text { - Considera apenas a perspectiva econômica; } \\
3 \text { - Orientada ao curto prazo; } \\
4 \text { - Busca reduzir a complexidade. }\end{array}$ & $\begin{array}{l}1 \text { - Ética, justiça, transparência e participação; } \\
2 \text { - Valores que suportem o desenvolvimento } \\
\text { sustentável, como balanceamento entre os fatores } \\
\text { econômicos, ecológicos e interesses sociais; } \\
3 \text { - Orientados ao curto e longo prazo; considera os } \\
\text { impactos além das entregas do projeto; } \\
4 \text { - Complexidade crescente. }\end{array}$ \\
\hline Desafios & $\begin{array}{l}\text { Resultados com visão de curto prazo não são mais } \\
\text { aceitáveis ou não proporcionam soluções sustentáveis. }\end{array}$ & $\begin{array}{l}1 \text {-Sobrecarga nas atividades de gerenciamento das } \\
\text { partes interessadas; } \\
2 \text { - Processo lento de tomada de decisão; } \\
3 \text { - Possível cancelamento do projeto ou entrega de } \\
\text { resultados pouco ambiciosos. }\end{array}$ \\
\hline
\end{tabular}

Nota: Fonte: Adaptado de Rethink! Project Stakeholder Management (2016). Disponível em https://www.pmi.org/learning/academic-research/rethink-project-stakeholder-management 


\subsection{Estruturas organizacionais e o papel do gerente de projetos na resolução dos conflitos}

A cultura e o estilo de organização afetam a maneira como ela conduz os projetos. O PMI, 5a edição (2013), afirma que a estrutura organizacional é um fator ambiental da empresa que interfere na disponibilidade dos recursos e na forma como os projetos são conduzidos. É possível afirmar que a maneira como a empresa organiza suas equipes e seu método de trabalho direciona esforços em torno do alcance de seus objetivos.

A estrutura matricial busca balancear as características da estrutura funcional, mantendo a divisão por especialidade em torno do gerente funcional, mas compondo equipes cedidas das diversas gerências em torno de um projeto conduzido por líder ou gerente de projeto. As organizações em forma de matriz são ditas fracas, balanceadas ou fortes a depender da dedicação e da autonomia do gerente de projeto.

Segundo Laslo e Goldberg (2008), conflitos em estruturas matriciais ocorrem quando objetivos incompatíveis entre gerentes de projeto e de operações aparecem. As necessidades imediatas dos gerentes de projeto para atendimento aos seus diversos requisitos requerem emprego imediato de recursos humanos, tanto cedidos das gerências internas da empresa quanto contratados externamente. As atividades operacionais e rotineiras, executadas pelas equipes que foram cedidas ao projeto, podem sofrer queda no desempenho ou descontinuidade temporária. Esta situação se agrava quando a organização conduz múltiplos projetos, desenvolvidos em diferentes etapas do seu ciclo de vida. Há necessidade de mediação para a solução destes conflitos típicos que são normalmente resolvidos por um superior hierárquico às duas gerências com visão estratégica do que é mais benéfico à organização.

As habilidades interpessoais e gerenciais se destacam como ferramentas necessárias para gerenciar as diversas partes interessadas. O PMI 5a edição (2013) afirma que elas devem ser usadas para "trabalhar com as partes interessadas para atender às suas necessidades/expectativas, abordar as questões à medida que elas ocorrem e promover o engajamento adequado das partes interessadas nas atividades do projeto". A importância do relacionamento nas questões do dia a dia é valorizada, pois novas questões surgem à medida que o projeto avança e elas 
devem ser discutidas de forma a resguardar o avanço do projeto e o atingimento dos seus objetivos.

Medina e Francis (2015) entrevistaram 15 profissionais de projetos de software e concluíram que um bom gerente de projetos tem as seguintes características principais, em ordem decrescente de importância:

1. É eficiente no planejamento das tarefas diárias;

2. É sociável, e demonstra interesse nos membros da equipe, tratando-os com respeito e sabendo balancear as demandas de trabalho com os aspectos sociais;

3. Permanece calmo em situações de estresse e crise;

4. Envolve os membros do projeto na tomada de decisão, fazendo uso da sua competência e experiência, mas sendo responsável pelas decisões;

5. Sabe dar feedback positivo quando merecido;

6. Sabe ser flexível e aberto a mudança, mas não precisa ser excessivamente carismático;

7. Tem conhecimento técnico suficiente para orientar os membros da equipe do projeto.

As características destacadas por Medina e Francis (2015) são contraditórias em alguns aspectos e demonstram os altos requisitos exigidos para qualificar um bom gerente de projetos. Ao passo que se espera deste a flexibilidade necessária para lidar com situações extemporâneas, os membros da equipe preferem que as atividades do dia-a-dia sejam planejadas e previsíveis. As situações extemporâneas surgem de solicitações de mudanças aprovadas, riscos identificados e não identificados que exigem respostas que devem ser propostas e executadas pelos membros da equipe cuja expectativa é ter rotina em suas atividades.

É possível deduzir que a habilidade de liderar em situações conflitantes é premente para os gerentes de projeto. Segundo Kerzner (2006), "os gerentes de projeto serão recompensados por sua habilidade de persuadir, influenciar, inspirar e negociar".

Ao lidar com equipes estruturadas matricialmente, o gerente de projetos tem desafios adicionais por ter que lidar com alterações na programação diária das atividades de seus colaboradores em função de demandas da rotina de suas 
gerências de origem. Em qualquer situação, o líder de projetos deve comunicar e negociar intensamente, buscando alinhar expectativas e definir responsabilidades, defendendo o seu interesse maior, que é concluir o projeto atendendo os requisitos previamente estabelecidos.

\section{Metodologia}

\subsection{Estudo de caso: projetos matriciais em uma empresa do ramo de óleo e gás}

O estudo de caso deste relato técnico buscou avaliar a influência do conflito no desempenho de projetos de Tecnologia da Informação e Telecomunicações - TIC conduzidos em estruturas matriciais numa empresa de óleo e gás. Os projetos de TIC são conduzidos em uma estrutura de matriz balanceada, pois os líderes de projeto têm dedicação em tempo integral e gestão completa sobre o orçamento do projeto, porém não têm gestão direta sobre as equipes de seus projetos. A metodologia de projetos de TIC reconhece a necessidade de mitigar os conflitos orientando o gerente de projetos a envolver constantemente as partes interessadas proporcionando alinhamento entre os participantes.

A metodologia de projetos da TIC foi avaliada com vistas a verificar sua influência na mitigação do conflito. A metodologia preconiza o envolvimento da equipe de operações nas diversas etapas do projeto: planejamento, execução e encerramento, apenas não ocorrendo na etapa de iniciação. O estudo de caso busca avaliar se a participação efetiva da equipe de operações para os projetos avaliados aumentou ou diminuiu o conflito.

No contexto do estudo de campo, definiu-se que a equipe de operações é parte interessada dos projetos em dois momentos distintos: em um primeiro momento como parte integrante da equipe durante a implantação do projeto; no segundo momento como responsável pelo recebimento e manutenção do sistema implantado ao longo do seu ciclo de vida. Os gerentes de projetos foram entrevistados por serem responsáveis pelo sucesso do projeto e, consequentemente, terem o dever de avaliar a influência do conflito e de definir estratégias para gerenciá-los.

A pesquisa de campo foi composta de um questionário com doze perguntas, divididas em dois blocos. O primeiro bloco, composto de 8 questões, mensurou a aplicação da metodologia avaliando o envolvimento da equipe de operações nas 
etapas do projeto. A participação da equipe de operações foi avaliada nas etapas descritas na Tabela 2.

\section{Tabela 2}

Avaliação do conflito com a equipe de operações

\begin{tabular}{|c|c|}
\hline ETAPAS DO PROJETO & DETALHAMENTO \\
\hline $\begin{array}{l}\text { a. PLANEJAMENTO: Projeto } \\
\text { conceitual }\end{array}$ & $\begin{array}{l}\text { Avalia a participação da equipe de operações na elaboração do } \\
\text { plano de gerenciamento do projeto e a influência desse fato na } \\
\text { redução do conflito }\end{array}$ \\
\hline $\begin{array}{l}\text { b. PLANEJAMENTO: Projeto } \\
\text { básico }\end{array}$ & $\begin{array}{l}\text { Avalia a participação da equipe de operações na definição dos } \\
\text { requisitos do projeto básico e a influência desse fato na } \\
\text { redução do conflito. }\end{array}$ \\
\hline $\begin{array}{l}\text { c. EXECUÇÃO: } \\
\text { Instalação }\end{array}$ & $\begin{array}{l}\text { Avalia a participação da equipe de operações no detalhamento } \\
\text { do cronograma de instalação e a influência desse fato na } \\
\text { redução do conflito. }\end{array}$ \\
\hline $\begin{array}{l}\text { d. ENCERRAMENTO do } \\
\text { projeto }\end{array}$ & $\begin{array}{l}\text { Avalia o grau de conflito na transferência do projeto para a } \\
\text { equipe de operações. }\end{array}$ \\
\hline
\end{tabular}

Nota: Fonte: Dados da pesquisa (2015).

O segundo bloco de perguntas, composto de 4 perguntas, avalia 0 desempenho do projeto. A Tabela 3 resume os critérios de desempenho do projeto avaliados no questionário.

\section{Tabela 3}

Critérios de avaliação do desempenho do projeto

\begin{tabular}{c|c}
\hline $\begin{array}{c}\text { CRITÉRIO DE } \\
\text { DESEMPENHO }\end{array}$ & DETALHAMENTO \\
\hline a. Custo & Compara o custo planejado (que foi entregue ao cliente no EVT) com \\
o custo realizado.
\end{tabular}

Nota. Fonte: Dados da pesquisa (2015).

O questionário completo é apresentado ao fim deste relato técnico.

\section{Resultados}

\subsection{Avaliações dos resultados do estudo de campo}


Os gráficos apresentados a seguir contêm informações extraídas dos 10 projetos de avaliados. As respostas extraídas do questionário são projetadas no eixo $Y$ com respeito às perguntas listadas no eixo $X$ de cada gráfico.

A Figura 1 ilustra o prazo realizado dos 10 projetos. Pode-se concluir pelas informações que muitos têm prazo significativo para conclusão, em alguns casos superando três anos para serem encerrados.

Prazo total dos projetos

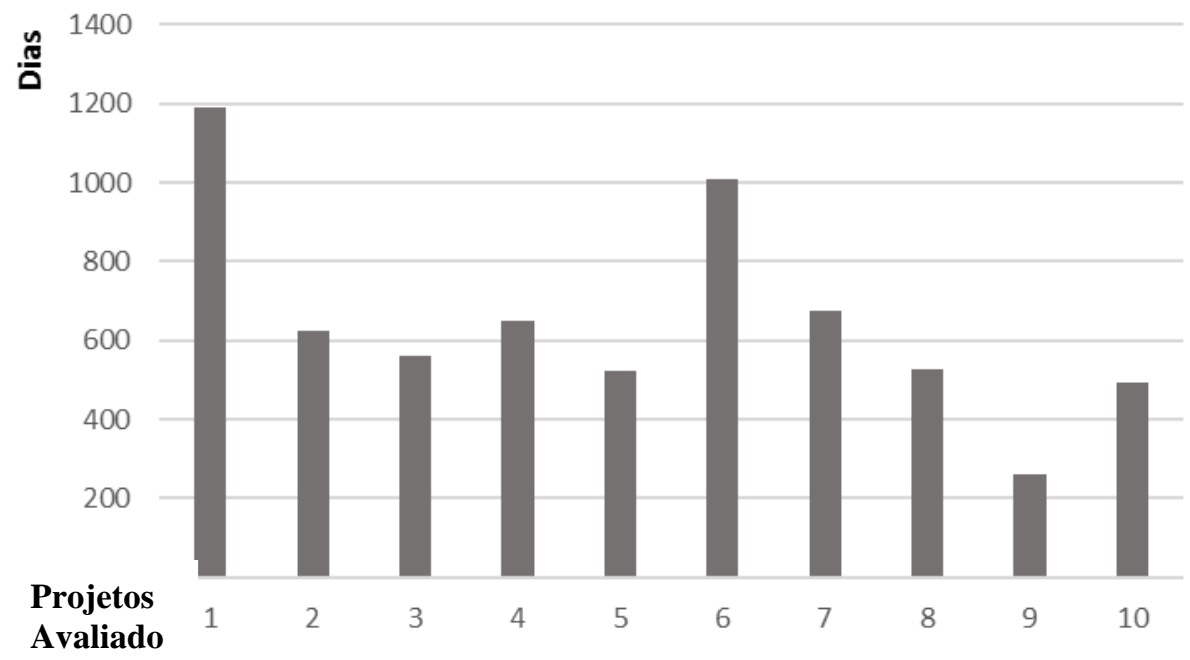

Figura 1

Prazo realizado dos projetos

Fonte: dados da pesquisa.

A Figura 2 explicita o custo realizado dos projetos estudados.

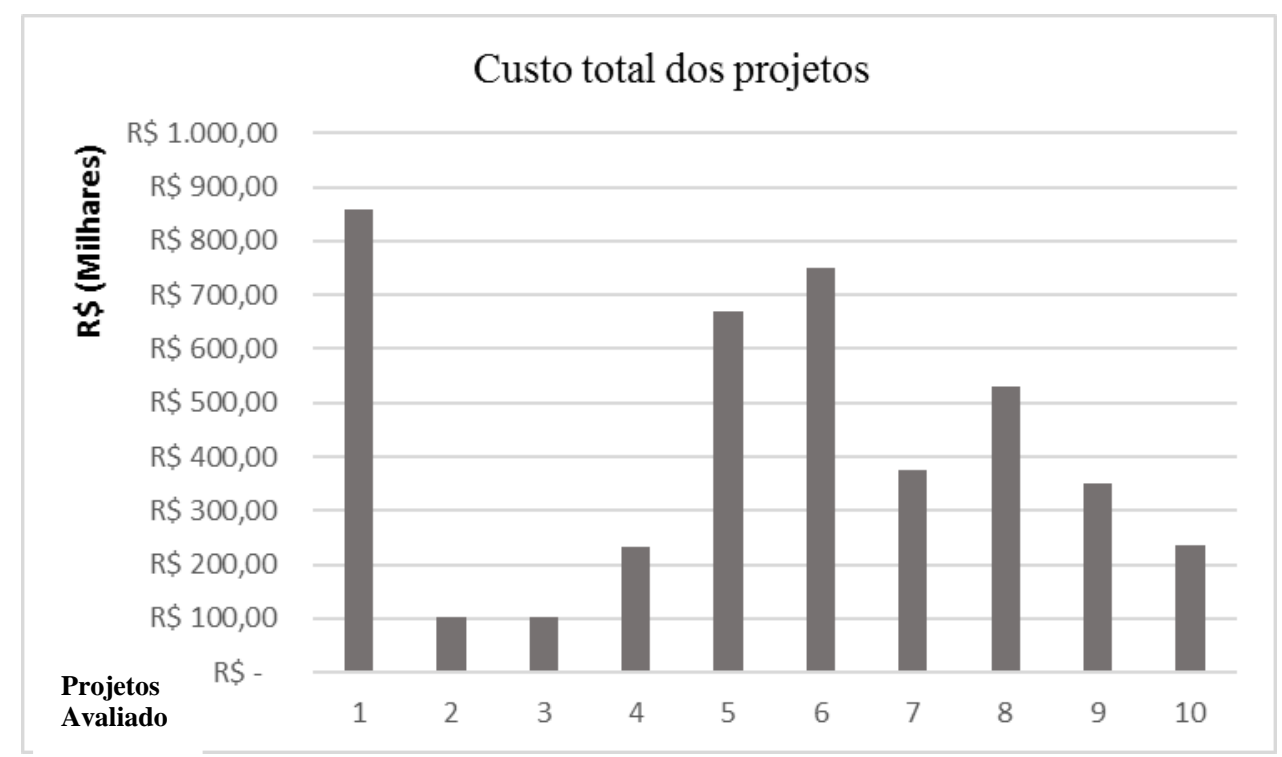

Figura 2

Custos realizado dos projetos

Fonte: dados da pesquisa. 
As 3 questões iniciais do primeiro bloco buscam confirmar se o líder de projeto envolveu a equipe de operações nas etapas de projeto conceitual (que é uma saída da etapa de planejamento), projeto básico e também na etapa de instalação. Essas questões encontram-se listadas na Tabela 4.

\title{
Tabela 4
}

Questões que avaliam o envolvimento da equipe de operações nas etapas de planejamento, projeto básico e instalação

\begin{abstract}
1. Na sua avaliação, as saídas do processo de planejamento foram elaboradas de forma participativa e negociada com a equipe de operações? Responda SIM ou NÃO.

2. $\mathrm{Na}$ sua avaliação, os requisitos do projeto básico (ver item 6.7.3 do padrão) foram elaborados de forma participativa e negociada com a equipe de operações? Responda SIM ou NÃO.

3. Avalie se o cronograma das atividades de instalação foi elaborado de maneira participativa e negociada com a equipe de operações. Responda SIM ou NÃO.
\end{abstract}

Nota. Fonte: Dados da pesquisa (2015).

A resposta aos questionários confirmou, para o universo de projetos pesquisado, que o envolvimento da equipe de operações é feito de maneira mais acentuada nas etapas de instalação. A Figura 3 evidencia esta participação; no eixo $Y$ tem-se o total de respostas iguais a "SIM" para as questões 1, 2 e 3, ao passo que no eixo $\mathrm{X}$ identificamos a questão correspondente.

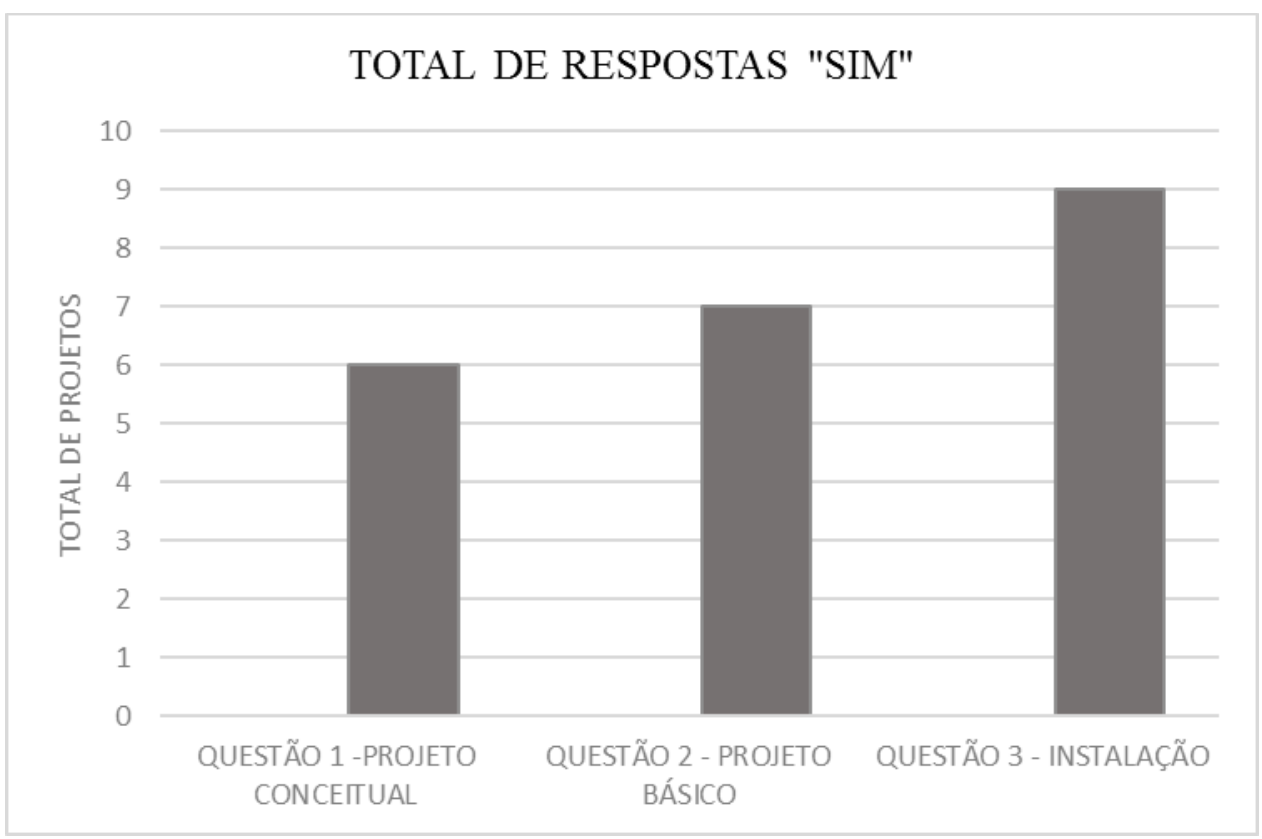

Figura 3 
Indicativo de participação da equipe de operações nas etapas de planejamento, projeto básico e instalação

Fonte: dados da pesquisa.

A elaboração do projeto conceitual foi elaborada de forma individual pelo líder do projeto em 4 dos 10 projetos de TIC avaliados, conforme se constata na resposta à questão 1. Verificou-se, posteriormente, com os entrevistados, que o uso de soluções padrões para projetos de TIC, previamente validadas pela área de operações, reduziu a necessidade de alinhamento entre as áreas para a elaboração do projeto conceitual. À medida que o projeto avança para a etapa de projeto básico (quando são elaborados os documentos técnicos para contratação de serviços, por exemplo), a interação entre as áreas aumentou, conforme se verifica na resposta à questão 2. A estratégia de contratação, através de contratos globais de suprimento, padronizou o processo de aquisições e reduziu a possibilidade de divergências. A elaboração do cronograma de instalação teve maior participação da equipe de operações, conforme se verifica na resposta à questão 3. Tal situação era esperada, considerando que as instalações ocorrem em ambientes controlados (salas de equipamentos e datacenters), que requerem planejamento prévio e autorização da equipe de operações para que a instalação dos novos equipamentos ocorra.

As 3 questões seguintes consideram as respostas das questões 1, 2 e 3 para avaliar a influência da metodologia de projetos da TIC na redução dos conflitos em projetos; as questões 4, 5 e 6 encontram-se listadas na Tabela 5:

\section{Tabela 5}

Influência da metodologia na redução de conflitos nas etapas de planejamento, projeto básico e instalação

4. Considerando a resposta à questão 1 , avalie se se a (não) participação da equipe de operações durante 0 processo de planejamento possibilitou a redução do conflito no relacionamento entre você e esta equipe ao longo do projeto. Pontue de 1 a 5.

5. Considerando a resposta à questão 2, avalie se a (não) participação da equipe de operações durante o processo de execução - fase de projeto básico - possibilitou a redução do conflito no relacionamento entre você e esta equipe ao longo do projeto. Pontue de 1 a 5.

6. Considerando a resposta à questão 3 , avalie se a (não) participação da equipe de operações na elaboração do cronograma possibilitou a redução do conflito no relacionamento entre você e esta equipe ao longo do projeto. Pontue de 1 a 5.

Nota. Fonte: Dados da pesquisa (2015).

As respostas às questões 4,5 e 6 pontuadas com os 2 maiores graus de concordância na escala de Likert de 5 níveis (respostas "totalmente de acordo" e 
"concordo") foram somadas. À esta soma de respostas e, consequentemente, de projetos com avaliações mais favoráveis, deu-se o nome de grau de favorabilidade. O grau de favorabilidade para as questões 4, 5 e 6 encontra-se indicado na Figura 4:

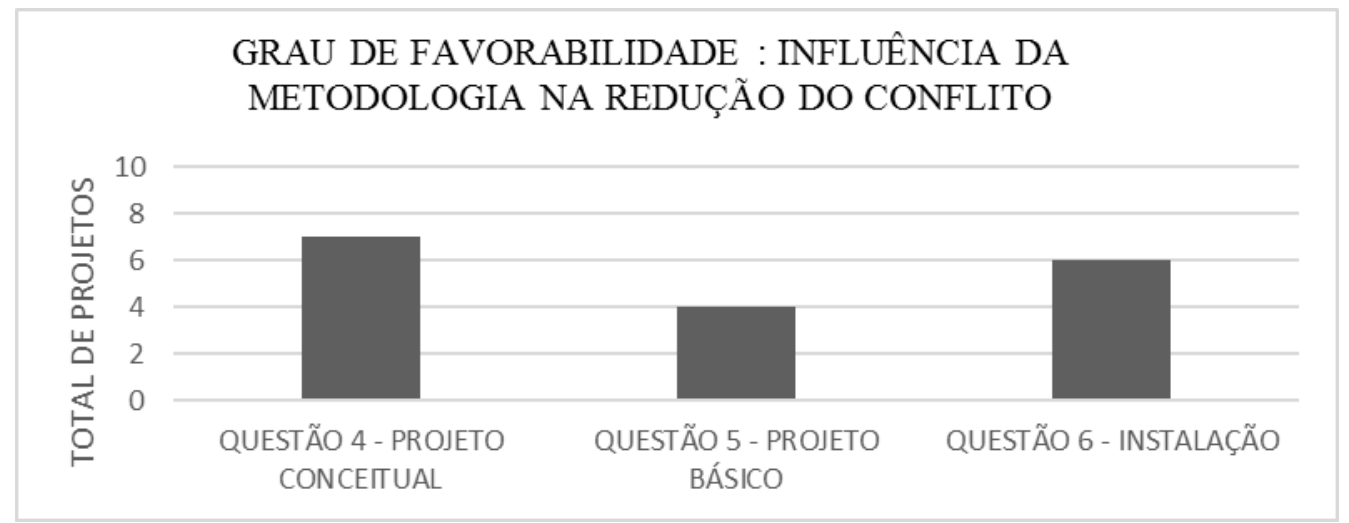

\section{Figura 4}

Grau de favorabilidade para a influência da metodologia de projetos da TIC na redução do conflito.

Fonte: dados da pesquisa.

O grau de favorabilidade para a etapa de projeto conceitual foi de 7 em 10 projetos avaliados. Como em apenas 6 a equipe de operações foi envolvida (segundo resposta à questão 1), depreende-se que não envolver os profissionais de operações na etapa de projeto conceitual também reduziu o conflito, contrariando as recomendações da metodologia de projetos de TIC. Isso é compreensível a partir da perspectiva de uso de uso de soluções técnicas padrões para conceituação do projeto. $O$ envolvimento da equipe de operações na etapa de projeto básico não contribuiu na redução do conflito de forma significativa, como é possível denotar da resposta à questão 5. Já para a etapa de instalação, a resposta à questão 6 indica, corroborando a resposta da questão 3 , que o envolvimento da equipe de operações reduz a possibilidade de conflito.

O encerramento do projeto é o momento mais crucial para a equipe de operações, pois neste momento ela se torna responsável pela manutenção do novo sistema ao longo do seu ciclo de vida. A questão 7 buscou avaliar o grau de conflito no encerramento do projeto. A questão 8 pede ao líder do projeto que analise a influência da metodologia de gerenciamento de projetos na gestão do conflito. As questões estão dispostas na Tabela 6. 


\section{Tabela 6}

Avaliação do grau de conflito no encerramento do projeto e influência da metodologia na administração de conflitos

7. Avalie o grau de conflito entre a liderança da equipe de projetos e a equipe de operações durante a transferência do sistema de telecomunicações projetado. Pontue de 1 a 5 , sendo 1: conflito inexistente; 2, pouco conflito, 3 - neutro (conflito administrado); 4 - muito conflito; 5 - conflito extremo.

8. Considerando a definição de conflito do início deste questionário, faça uma análise do quanto a metodologia de gerenciamento de projetos o auxiliou a administrar este conflito. Avalie também quanto o conflito influenciou no desempenho deste projeto

Nota. Fonte: Dados da pesquisa (2015).

O grau de favorabilidade foi aplicado para a questão 7 da Tabela 6. As respostas à questão 7 seguem na Figura 5 , onde 0 eixo $X$ corresponde à questão respondida, enquanto o eixo $\mathrm{Y}$ indica as respostas obtidas para os 10 projetos.

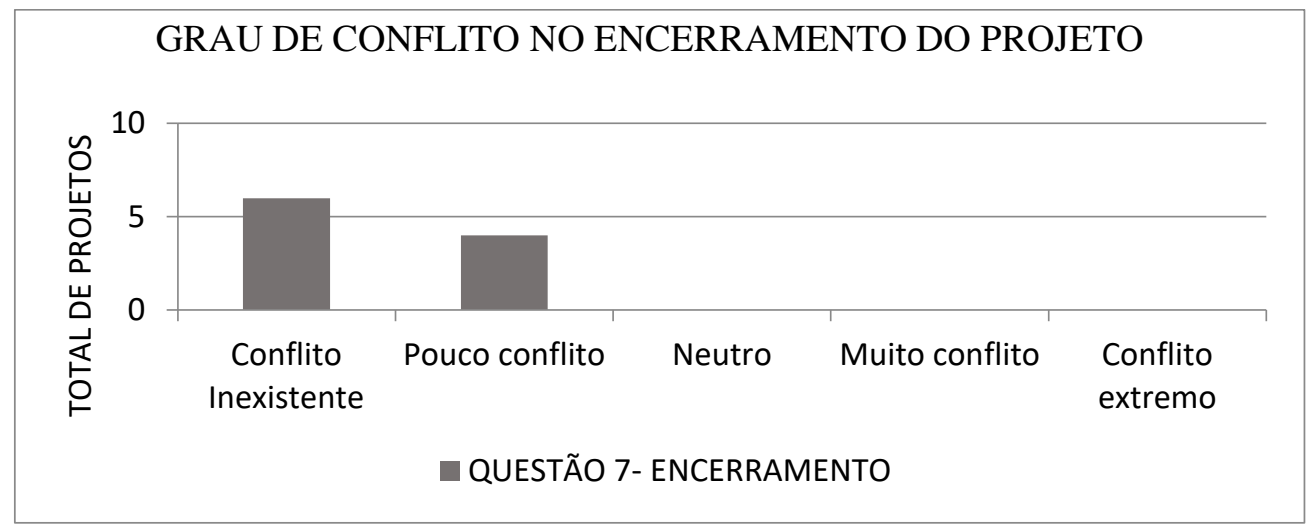

Figura 5

Grau de conflito no encerramento do projeto Fonte: dados da pesquisa.

As respostas à questão 7 , juntamente com as respostas às questões 1,2 e 3 descritas na Tabela 4 possibilitam concluir que a participação da equipe de operações nas etapas de projeto básico (questão 1.3) e instalação (questão 1.5) permitiu que os projetos fossem conduzidos de maneira harmônica, ou seja, com conflito inexistente ou pouco conflito.

A questão 8 teve respostas abertas, que indicaram a presença de pequenos conflitos gerenciados pelos líderes de projeto. A

Tabela 7 contém algumas dessas respostas. 


\title{
Tabela 7
}

Influência da metodologia de gerenciamento de projetos de TIC no gerenciamento do conflito

\begin{abstract}
1. "Após a identificação de conflitos entre as áreas de implantação e operação, o gerenciamento das comunicações no projeto foi intensificado, através da realização de reuniões presenciais periódicas em diversos níveis: reuniões amplas, com a participação de representantes de todas as equipes de operações envolvidas no projeto; reuniões setoriais, com cada equipe de operação; reuniões pessoais, com cada profissional-chave envolvido no projeto ("tete-à-tete"). Essa tática mostrou-se eficaz na mitigação dos conflitos. No que tange à influência dos conflitos no desempenho do projeto, pode-se dizer que o principal reflexo da sua existência se apresentou no prazo de conclusão do projeto, que foi maior que o originalmente planejado. Em alguns momentos, a priorização, pela equipe de operação, das atividades de manutenção - sobretudo atividades não planejadas impediu que certas atividades de implantação fossem realizadas na data planejada".
\end{abstract}

2. "O pequeno conflito existente ocorreu apenas na fase de transferência do sistema para a área de operações, referente à aceitação de pendências não impeditivas por parte da área de operações. Após entendimentos, estas (pendências) foram registradas em atas de reunião e, portanto, este conflito não influenciou o desempenho do projeto".

3. "A metodologia não influenciou nesta situação."

Nota. Fonte: Dados da pesquisa (2015).

O uso intensivo de técnicas de comunicação conforme orienta a metodologia de projetos de TIC foi aplicado de forma proativa, o que minimizou a influência do conflito durante as etapas do projeto, em particular ao se aproximar do seu encerramento. $\mathrm{O}$ registro das comunicações e a definição clara de responsáveis por eventuais pendências não impeditivas de aceitação trouxeram transparência e tranquilidade à equipe de operações, reduzindo as chances de influência negativa do conflito nos resultados do projeto.

As questões 1 a 4 do bloco 2 do questionário referem-se ao desempenho do projeto com respeito a custos, prazo, satisfação do cliente e desempenho técnico da solução. As 4 questões do bloco 2 seguem relacionadas na Tabela 8.

\section{Tabela 8}

Avaliação do desempenho do projeto com respeito a custos, prazo, satisfação do cliente e desempenho técnico

\footnotetext{
1. Considerando o custo inicialmente planejado (conforme EVT aprovado do projeto): avalie 0 desempenho do projeto usando a escala de 1 a 5 ;

2. Considerando o prazo inicialmente planejado (conforme EVT aprovado do projeto): avalie o desempenho do projeto usando a escala de 1 a 5 ;

3. Considerando a satisfação do cliente com respeito ao produto entregue: avalie o desempenho do projeto, usando a escala de 1 a 5 ;

4. Leia novamente a definição de stakeholder atribuída a equipe de operações. Considerando esta definição, sobre a perspectiva desta parte interessada, avalie o desempenho técnico da solução usando a escala de 1 a 5 .
}

Nota. Fonte: Dados da pesquisa (2015). 
Uma escala de Likert com 5 níveis foi aplicada às respostas dessas perguntas. O grau de favorabilidade para as 4 questões foi aplicado e segue ilustrado na Figura 6 .

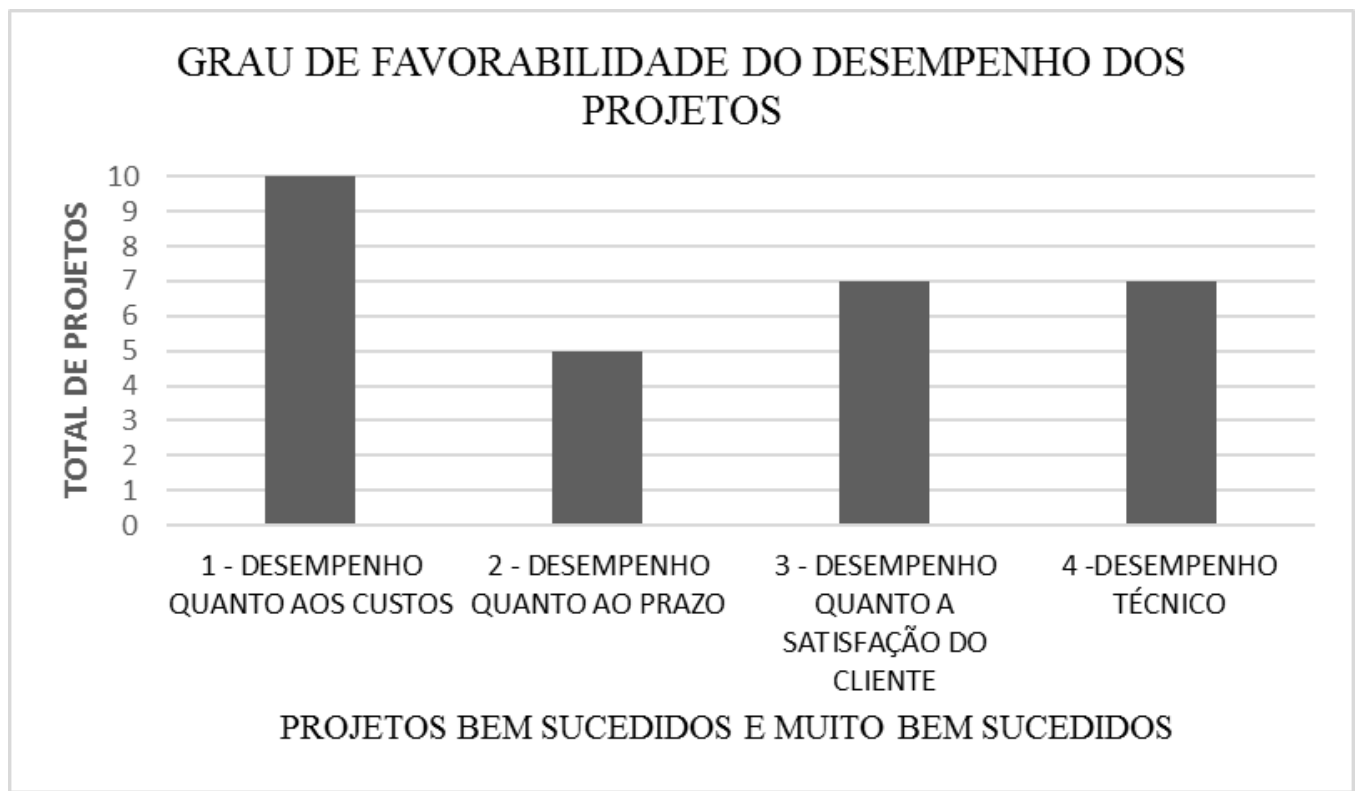

Figura 6 - Grau de favorabilidade com respeito ao desempenho dos projetos quanto a custo, prazo, satisfação do cliente e desempenho técnico.

Fonte: dados da pesquisa.

Os projetos tiveram muito bom desempenho quanto a custos e $70 \%$ deles tiveram boa avaliação tanto com respeito à satisfação do cliente quanto no desempenho técnico avaliado pela equipe da área de operações. Por outro lado, apenas $50 \%$ dos projetos foram considerados como bem-sucedidos quanto ao prazo esperado. No entendimento dos gerentes de projetos, a falta de dedicação da equipe matricial do projeto, oriunda da área de operações, concorreu para o atraso das atividades e, consequente, o descumprimento do cronograma. A priorização das atividades de rotina pela equipe de operações aparece como elemento que compromete o desempenho do projeto com respeito ao prazo planejado.

\section{Considerações finais}

O conflito entre os líderes de projetos e as equipes de operações, segundo análise dos primeiros, pouco influenciou nos resultados do projeto. Uma explicação para isso é que a metodologia de gestão de projetos tornou a redução do conflito possível quando incentivou o envolvimento entre as equipes de operações e as lideranças dos projetos. $O$ desempenho quanto aos custos foi bem avaliado em 
todos os projetos, assim como a satisfação geral do cliente e da equipe de operações, que apresentou grau de favorabilidade de $70 \%$. Contudo, o grau de favorabilidade do desempenho quanto ao prazo do projeto teve avaliação insatisfatória, com valor igual a 50\%. Uma das causas possíveis desse baixo índice é a sobreposição de atividades de rotina da gerência de operações sobre atividades de projeto, motivada pela dupla hierarquia entre gerentes de operações e gerentes de projeto nas equipes envolvidas. Devido a alterações de prioridades, as atividades de projeto são postergadas e isto conduz a atraso na sua conclusão.

Outra possível causa da ausência de conflito é a predominância de gerentes de projeto com perfil esquivo à resolução de conflitos, que tendem a priorizar a estabilidade nas relações humanas em detrimento dos resultados do projeto. $\mathrm{O}$ baixo grau de favorabilidade no desempenho quanto ao prazo do projeto pode indicar uma possível predominância do perfil esquivo de negociação entre os gerentes cujos projetos tiveram desempenho ruim quanto aos prazos.

Por fim, outra explicação para a baixa influência do conflito é que apenas o líder de projeto foi entrevistado. A avaliação de desempenho dos projetos considerou os requisitos clássicos do triângulo das restrições (atendimento ao prazo, custo e satisfação do cliente ou escopo definido) que são prioritários para o gerente de projetos. A avaliação do grau de satisfação da equipe de operações precisa ser corroborada com a opinião destas partes interessadas para garantia de confiabilidade. A visão de longo prazo preconizada pelo modelo de gerenciamento para as partes interessadas requer maturidade dos líderes de projeto, que não pôde ser comprovada nesta pesquisa. Essa constatação abre oportunidades para uma futura pesquisa, que poderá comparar esses resultados obtidos com a opinião da própria equipe de operações que compõe os projetos.

Outra oportunidade de pesquisa é a condução de projetos simultâneos. A gestão de múltiplos projetos e o compartilhamento de recursos especializados é um desafio que não deve ser desprezado, pois a coordenação de múltiplos projetos nas suas diversas etapas (iniciação, planejamento, execução e encerramento) implica em restrições adicionais de recursos críticos que podem deteriorar o desempenho dos projetos e aumentar o conflito entre as partes interessadas. Um estudo futuro pode analisar a gestão de múltiplos projetos e a aplicação de diversas técnicas, entre elas a teoria da restrição (T.O.C.), em projetos conduzidos em estruturas 
matriciais, tanto em empresas do segmento de óleo e gás quanto do segmento de Tecnologia da Informação e Telecomunicações.

\section{Referências}

Freeman, R.E. (1984). Strategic management: A stakeholder approach. Boston: Pitman.

Huemann, M., Eskerod, P., \& Ringhofer, C. (2016). Rethink! Project stakeholder management. Pennsylvannia: Project Management Institute, Inc.

Laslo, Z., \& Goldberg, A. I. (2008). Resource allocation under uncertainty in a multiproject matrix environment: Is organizational conflict inevitable? International Journal of Project Management, 26, 773-788.

Kerzner, H. (2006). Gestão de Projetos, as Melhores Práticas. Porto Alegre: Bookman.

Medina, A., \& Francis, A. J. (2015). What are the characteristics that software development Project team members associate with a good Project manager? Project Management Journal, 46, 81-93.

Mitchell, R. K., Agle, B.R., \& Wood, D.J. (1997). Toward a theory of stakeholder identification and salience: defining the principle of who and what really counts. The academy of Management Review, 22, 853-886.

Morrison, J. M., Brown, C.J., \& Smit, E. (2008). The impact of organizational culture on project management in matrix organizations. South African Journal of Business Management, 39, 27-36.

Pfeffer, J., \& G. R. Salancik (1978). The External Control of Organizations: A Resource Dependence Perspective. New York, NY, Harper and Row.

PMI - Project Management Institute. (2013). Um Guia do conhecimento em gerenciamento de projetos - Guia PMBOK (5a ed.). Pennsylvannia: Project Management Institute, Inc.

Savage, G.T., Nix, T.W., \& Blair, J.D. (1991). Strategies for assessing and managing organizational stakeholders. Academy of Management Executive 5(2), 61-75.

Sbragia, R. (1989). Estilos participativos de decisão e desempenho de projetos em estruturas matriciais. Revista de Administração, São Paulo, 24, 48-61.

Shell, Richard G. (2001). Bargaining Styles and Negotiation: The Thomas-Kilmann Conflict Mode Instrument in Negotiation Training . Negotiation Journal, 155-174. 